\title{
The new business is circular? Analysis from the perspective of the circular economy and entrepreneurship
}

\author{
Edson Luis Kuzmaa* (D), Simone Sehnem (D), Hilka Pelizza Vier Machado ${ }^{\mathrm{a}}$ (D), \\ Lucila Maria de Souza Campos ${ }^{\mathrm{b}}$ \\ anniversidade do Oeste de Santa Catarina, Chapecó, SC, Brasil

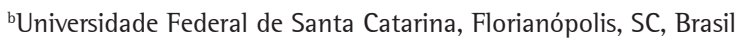 \\ *edson.kuzma@gmail.com
}

\begin{abstract}
Paper aims: The objective of this article is to explore the relationship between circular economy and entrepreneurship, to propose an agenda for future research to advance in the field and generate managerial implications.

Originality: The study helps to identify the research profile and enable the development of a logical structure for analyzing entrepreneurship carried out in the specific context of companies operating under the guidance of the circular economy.

Research method: The method is a systematic literature review, peer-reviewed and indexed in ten databases. The research protocol adopted aimed at: i) searching and searching the databases, ii) sorting and selecting the literature, iii) coding and analyzing the data.

Main findings: The results point to: i) predominance of causation logic in the market environment, ii) attention to the creation of relationship and value networks, iii) entrepreneurship aimed at valorization, iv) focus on innovation in production, regional development and exploitation of market failures.

Implications for theory and practice: The main contribution of the study is to consolidate the knowledge in the field of circular economy and entrepreneurship, still little explored. The results provide a basis for managers and decision-makers to expand their business and create new models based on the circular economy.
\end{abstract}

Keywords

Circular economy. Entrepreneurship. Circular business models. Entrepreneurial behavior. Sustainability.

How to cite this article: Kuzma, E. L., Sehnem, S., Machado, H. P. V., \& Campos, L. M. S. (2021). The new business is circular? Analysis from the perspective of the circular economy and entrepreneurship. Production, 31, e20210008. https:// doi.org/10.1590/0103-6513.20210008.

Received: Feb. 9, 2021; Accepted: Oct. 4, 2021.

\section{Introduction}

Circular Economy (CE) prioritizes the modification of traditional production and consumption models. The linear processing logic focused on use-disposal transits to circular production systems and differentiated business models with the objective of eliminating waste and material and energy waste (Julianelli et al., 2020). The transition from linear production model to the gradual insertion of circular logic implies and is conditioned by the adoption of technology, which leads to the intelligent decentralization of production, the use of reusable materials and the extension of product life (Kravchenko et al., 2020).

Initiatives to stimulate and awaken to the CE are growing at the same time as new highly dynamic business models are being created that are focused on offering fast solutions to consumers (Henry et al., 2020). In recent years, start-ups have been created to address innovative forms of consumption. This enables the creation of 
new market categories through entirely circular business (Singh \& Singh, 2019; Henry et al., 2020). Sharing platforms, for example, bring together resources and alternatives that stimulate and enable the insertion of the sharing economy, a subject strictly related to the premises of the CE (Konietzko et al., 2020).

However, there is still a gap in the scientific literature that is associated with an understanding of how the premises of the CE can be internalized by sustainable entrepreneurship. Although there are studies that signal the approximation of the CE and sustainable entrepreneurship (Brendzel-Skowera, 2019; Flygansvær et al., 2019), this approximation of concepts is necessary and demands further analysis and reflection on how it can be done, benefits it can generate for society and advances in favor of the circularity of resources it can provide. Considering the existence of this theoretical gap, this study contributes with a revision approach on business creation and entrepreneurship studies, with attention focused on the insertion and consolidation of CE as a principle and practice. No other review study with this scope has been identified in the literature. It is remarkable that the field is in a diffuse direction, which makes it possible and opportune to develop a revision. The identification of the research profile and the development of a logical structure of analysis of entrepreneurship was carried out in the specific context of companies operating under the guidance of the CE. Therefore, it was possible to present an analysis of scenarios in which the CE and entrepreneurship are articulated in the definition of their actions.

It is relevant that entrepreneurs ratify a pro-entrepreneurial attitude to support the process of transition of companies and industries towards the transition to circular models (Frishammar \& Parida, 2019). Theoretical discussions on circular economy and the creation of new businesses in the entrepreneurial context must be approached in different areas of knowledge, to promote additions to the knowledge that already exists about environmentally and socially responsible clocks (Alonso-Almeida et al., 2021). Especially in the context of new technologies and wide access to information, there is an increasing progress towards the frontiers of efficiency and optimization in the use of resources, which allows the improvement of the added value to products and components (Peiró et al., 2020).

This study includes a theoretical and managerial contribution by analyzing the panorama of scientific production associating the themes of CE and entrepreneurship. The parallel between sustainable entrepreneurship and other entrepreneurs focused on sustainability, as in the case of social entrepreneurship, is directly associated with the management of tensions generated by various forms of value creation (Defourny \& Nyssens, 2012). In terms of scientific progress, it is opportune that the field obtains greater uniformity and that perspectives for future research are outlined. The definition of gaps and possibilities for exploration establishes the next stages to be advanced. The managerial contribution lies in providing entrepreneurs with a holistic view of the present scenario of creating businesses connected to the CE. From each analytical category it is possible to perceive how the phenomena of entrepreneurship and CE connect and behave.

In this context, the article offers a contribution towards codifying and categorizing advances already registered in research and practices in the field. Entrepreneurs are often unable to identify and seek opportunities for circular economy, which makes the advances, although highly necessary, relatively timid in relation to their effective potential (Millette et al., 2020). As the economy circulates, it reinvents the waste of resources and energy in economic opportunities to be explored, opportunities for exploitation by entrepreneurs are created (Pizzi et al., 2021). In this context, the field needs consistent advances to consolidate the knowledge produced, support and guide future advances in the analysis of the circular economy and entrepreneurship. It is noteworthy that the understanding and exploitation of entrepreneurship for circular economy is limited in the literature (Cullen \& De Angelis, 2021) and its implementation through business models is still unusual.

The transition from the traditional or conventional economic model to a linear system of production and consumption necessarily implies a change in the logic of resource use. Changing this logic requires new ideas, new products, differentiated design, new businesses and projects aligned with principles of innovation and focused on optimizing the use of resources. In this sense, this study explores the relationship between circular business models and entrepreneurship to understand the interaction and integration of both fields to promote advances in the practice of organizations.

The purpose of this article is to analyze the relationship between EC and entrepreneurship, with the categorization of studies and propose an agenda for future research that advances in the field and generates managerial implications on the subject. The analysis reveals insigths that contribute to the consolidation of the interface between the themes and provides advancement for academia and entrepreneurs. To explore the theme, it is proposed to categorize the revised studies from sets of descriptive and analytical dimensions. The descriptive dimensions refer to the characteristics of the articles, such as type of economy in which it was developed, sector of action of the companies, among others. The analytical dimensions explore themes related to the consolidated literature on entrepreneurship, through which the studies are classified into different conceptual logics. 
The study is structured in seven main sections. Section 2 provides the theoretical framework that guides and underpins the research. Section 3 describes the research method and procedures. Section 4 presents the results of the systematic review, with the extraction of the data resulting from the mapping of papers and definition of the categories of analysis. Section 5 discusses the results found, proposing connections and interactions on the subject. Section 6 presents the gaps and possibilities for future research, with the schematization of proposals to be explored as research agenda. Section 7 concludes the study, presenting implications for research and limitations.

\section{Theoretical framework}

The circular business model demands the reorganization of processes and business partnerships to create a structure that supports and supports sustainability. The closing of production cycles covers economic, environmental and social aspects of the system, stimulating and triggering conscious consumption and rational use of materials and energy. It is essential to emphasize that it is not only the more conscious use of resources and energy, but the effective systemic insertion of sustainable practices, the development of the product for final destination in post-use (Kristensen \& Mosgaard, 2020). This necessarily implies planning and orientation for long-term results (Konietzko et al., 2020). The circular business model therefore demands the reorganization of processes and business partnerships to create a structure that supports and is compatible with sustainability.

The strategy of the CE is based on actions to reuse, reduce and recycle the use of materials, reuse and reduce energy consumption, reduce and reuse materials previously considered waste (Chiappetta Jabbour et al., 2019; Julianelli et al., 2020). In this sense, moving from the linear model to the circularity of the economy demands innovation and change. The practical challenge associated with this transition requires interdisciplinary mobilization and focus on the life cycle of products. In fact, experimentation is an important factor in triggering sustainability and is an essential component for understanding the transitions and changes in the business context (Millette et al., 2020). The success of the attempt to obtain the best performance in sustainability is also conditioned by the context and allows exploring the different possibilities through which the company can generate value. The value to be generated from the company itself or from new business models (Schaltegger et al., 2016).

Business experimentation applies to the exploration of differentiated opportunities to add value to the product or service. This can occur by reducing resource consumption, time and opportunity cost (Rey-Martí et al., 2021). The process of identifying opportunities and creating new businesses in the face of uncertainties is common to the environment in which changes operate to close production cycles towards the CE (Konietzko et al., 2020). Experimentation for the transition towards sustainability is influenced by the context and opportunities for value creation (Kristensen \& Mosgaard, 2020). Its assimilation involves identification, testing and learning about new strategies for sustainable value generation. In this sense, business experimentation for the CE can be best explained by effectuation-type approaches, given the uncertainty inherent in such businesses.

The literature on the interface between the CE and entrepreneurship is still limited (Heshmati, 2017). Researchers assign the term "ecopreneurship" to label entrepreneurs who guide their businesses by environmentally oriented activities (Schaltegger, 2002). In businesses guided by the linear logic of production, profits are the ultimate goal and focus. In the circular conception, besides these, environmental objectives are included as a factor that guides and defines the business directions. Above all, the retention of the value of resources in supply chains (Amoako et al., 2021).

The adoption of the CE as a way of proposing new businesses faces barriers to its implementation. The difficulties in recognizing and developing opportunities for business models is one of these barriers (Tura et al., 2019). This occurs because of the need to map possible alternatives to be taken advantage of, since without the identification of opportunities or generation of alternatives there is no field for advancement (Millette et al., 2020). Weaknesses in entrepreneurial learning are conditioning elements of barriers. The exploration of new opportunities to create socio-environmental value involves the generation of capacity to protect the environment and people (Lynde, 2020). These barriers must be overcome in order to correct the imperfections of the traditionally widespread linear logic that contributes to environmental pollution, a fundamental premise for the incorporation of the CE and the enhancement of entrepreneurial activity.

\section{Method}

The method adopted in this research is a systematic review of literature. The research protocol developed by Tranfield et al. (2003) was adopted, consisting of three main steps: i) database search and selection, ii) literature screening and selection, iii) data coding and analysis. Other recent revisions adopt a similar procedure 
for data selection, extraction and codification (Bansal et al., 2020; Bressanelli et al., 2020; Fernandes et al., 2020). The documents were restricted to peer-reviewed articles, in order to assess the higher quality of the reviewed material.

In the first stage, strings were selected and database searches performed. The search terms were defined by testing the strings used in other reviews in the field of circular economics and entrepreneurship. In order to reach the results, 10 databases were included to search the articles. The bases adopted were: Scopus, Web of Science, ScienceDirect, Emerald, Google Scholar, Wiley Online Library, Sage, Springer, Taylor and Francis and JSTOR. The search terms were associated with variations of the keywords "circular economy" and "entrepreneurship". The final search was performed on May 07 and 09, 2021, without any chronological restrictions. The strings were identified in the title, abstract, keywords and content. The return was 3,554 documents. Table 1 presents the results.

Table 1. Results of the execution of searches.

\begin{tabular}{|c|c|c|c|}
\hline \multicolumn{4}{|c|}{ Paper Stratification } \\
\hline & Combinations & Subject/Base & Papers \\
\hline \multirow{10}{*}{$\begin{array}{l}\text { “Circular } \\
\text { Economy"AND } \\
\text { "entrepreneurship" }\end{array}$} & \multirow{10}{*}{ 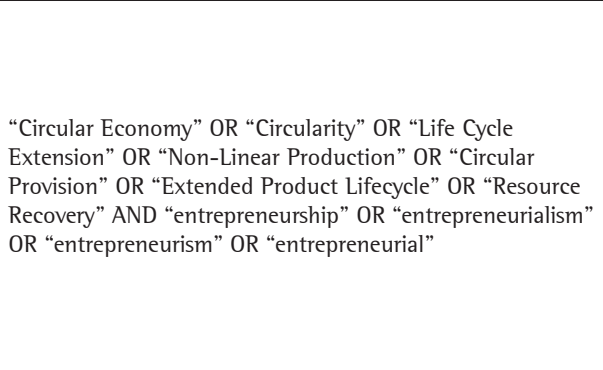 } & Scopus & 186 \\
\hline & & Web of Science & 180 \\
\hline & & Science Direct & 1614 \\
\hline & & Sage & 16 \\
\hline & & Emerald & 490 \\
\hline & & Proquest & 321 \\
\hline & & Wiley Online Library & 115 \\
\hline & & Springer & 392 \\
\hline & & Taylor and Francis & 122 \\
\hline & & JSTOR & 118 \\
\hline Total & & & 3554 \\
\hline
\end{tabular}

In the second stage, the articles were sorted and the preliminary reading of the work was done. The following exclusion criteria were adopted: i) works with a different format or type of article or article in press, ii) duplicate or redundant studies (only one of the studies found was considered), iii) studies published in summary format, iv) impossibility of locating the entire document file online, v) studies written in a language other than English, vi) studies that do not address circular economics and entrepreneurship, or whose focus is not aligned with the scope of the research. No segmentation criteria based on the area of study or methodology were used. The verification of the adequacy of the study to the scope of the research was carried out from the reading of the titles, abstracts and keywords. After applying the exclusion criteria, we obtained the final sample of 40 works included for the analysis.

The third stage includes the extraction of results and categorization based on theoretical arguments. The articles were read in full in order to identify information relevant to the characterization of the theme and studies and to define analytical categories. The information was extracted and tabulated in an MS Excel database. The documents were recovered and analyzed for the tabulation of bibliometric information, such as authorship, year of publication, area of knowledge, host country, applied sector, guiding concept of the research, journal of the publication, modality of economy, main results, limitations and recommendations, among other information. After the survey of descriptive information, analytical categories were defined to deepen the analysis of the results, demonstrating the perspectives and possibilities for advancement in the subject based on the limitations of previous studies.

The key themes of the analytical categories for development and contextualization of the insertion of the CE in the constitution of new businesses, via entrepreneurship, came from the visualization of the articulation of the areas and the direction that the advance of the field demonstrates. The data was analyzed through a dynamic process of definition, classification, categorization and reading of existing relationships. Codification was adopted with theoretical arguments not yet addressed in other review studies, to ensure the novelty of the results. Based on the arguments discussed, perspectives are drawn for future studies in the area.

The steps and general procedures of the research are presented in Figure 1. 


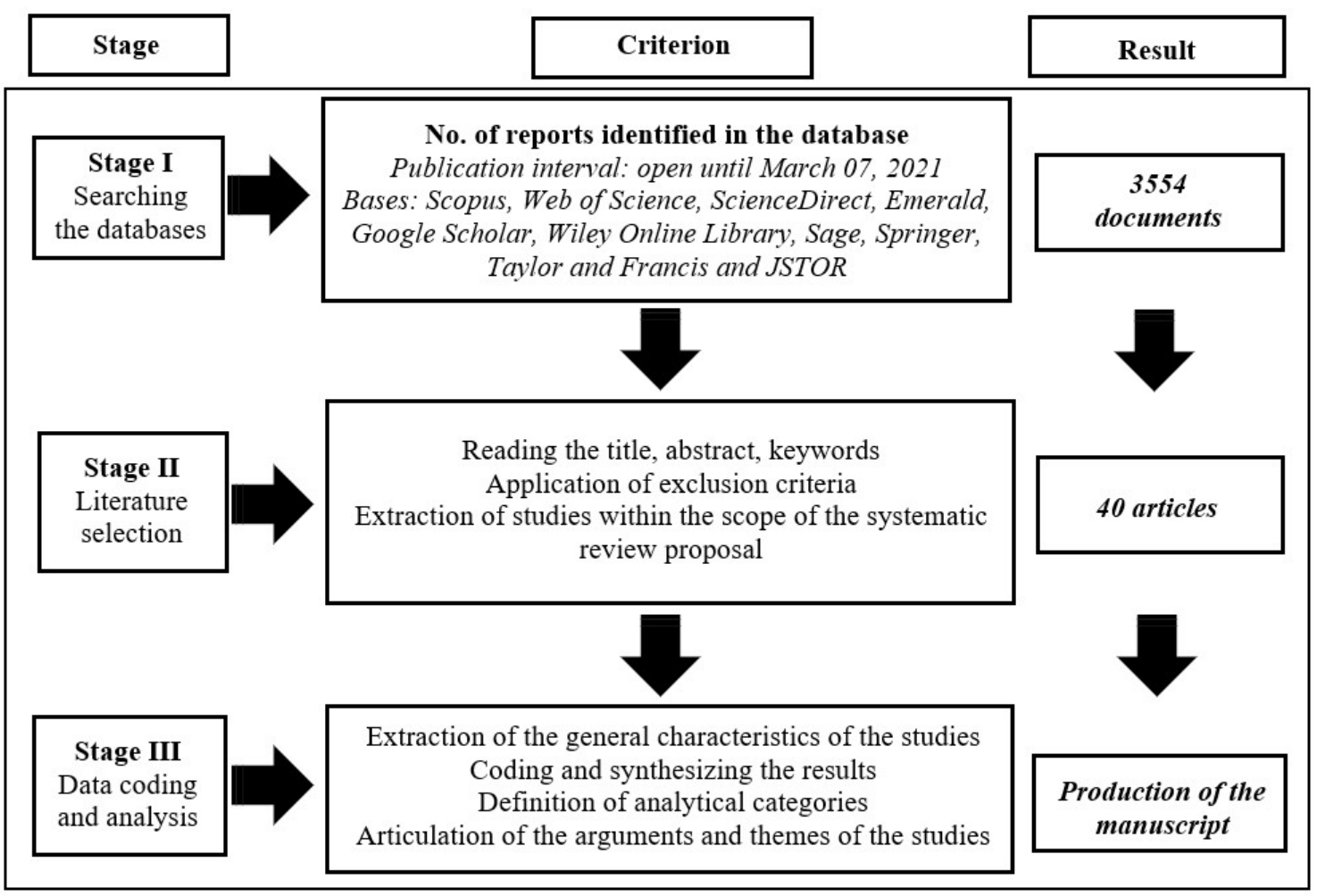

Figure 1. Systematic review procedures.

\section{Literature results}

Based on the application of the inclusion and exclusion criteria, following the research and information gathering protocol, a total of 40 articles were obtained. The studies mapped by the systematic review follow different lines of exploration in relation to the theme, demonstrating the plurality of possibilities explored in this area of research. The studies integrate and articulate the understanding of the entrepreneurial process in the context of business focused on the circular production model. It is assumed that companies that adopt CE practices differentiate themselves from others that do not, especially in the aspect of production processes and operations, as well as in the interaction of the organization with its various stakeholders.

In relation to the publication period, it should be noted that productions have been accumulated in recent years, especially in 2019 (19 papers), 2018 (12 papers) and 2019 (6 papers). The year 2017 has only three publications. The report on practices related, especially to the CE, and mentioned in the studies analyzed follows a process of consolidation of the theme as a research locus. If indeed, the theme is emerging as an area of research, derived from another area of broader discussion that involves sustainability. In terms of epistemological orientation, the CE follows an accelerated rhythm of interest from researchers, but still demands deepening. The combination of the area with the theme of entrepreneurship, as occurs with other themes, such as innovation (Antikainen \& Valkokari, 2016), results in subjects that are still little explored. Figure 2 presents the concentrations of publications per year.

In relation to the Journals that publish on the subject, what is noticeable is the concentration that occurs with a periodical, which in general is also the one that most disseminates, in terms of quantity, articles on CE. The information is shown in Table 2.

It is noticeable that the Journal of Cleaner Production stands out from the others, accumulating 28\% of production. It is noteworthy that the mentioned journal has a high impact factor, which indicates that the production on the subject, in considerable proportion, presents quality and relevance to the academic environment. The other journals present one or two publications. It is important to highlight that most journals register an impact factor, evidencing the quality of the debate around the themes. 


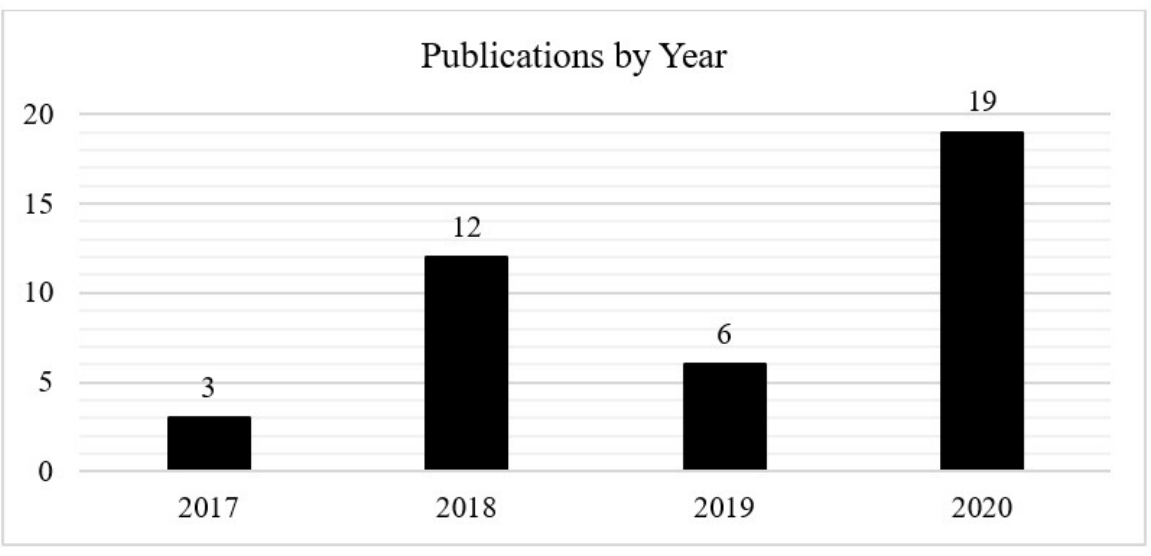

Figure 2. Number of Publications per Year.

Table 2. Journals by Publication Number.

\begin{tabular}{lccc}
\hline \multicolumn{1}{c}{ Journal } & Freq. Absolute & Freq. Relative & Impact Factor JCR \\
\hline Journal of Cleaner Production & 11 & $28 \%$ & 7.246 \\
Sustainability & 6 & $15 \%$ & 2.576 \\
Forest Policy and Economics & 3 & $8 \%$ & 3.139 \\
Resources, Conservation \& Recycling & 3 & $8 \%$ & 8.086 \\
Sustainable Production and Consumption & 2 & $5 \%$ & 3.660 \\
Business Strategy and the Environment & 1 & $3 \%$ & 5.483 \\
Corporate Governance & 1 & $3 \%$ & - \\
Economic Research & 1 & $3 \%$ & - \\
Entrepreneurship and Sustainability lssues & 1 & $3 \%$ & 0.775 \\
FlBRES \& TEXTlLES in Eastern Europe & 1 & $3 \%$ & 3.472 \\
International Entrepreneurship and Management Journal & 1 & $3 \%$ & 3.529 \\
International Journal of Entrepreneurial Behavior \& Research & 1 & $3 \%$ & - \\
International Journal of Entrepreneurship and lnnovation Management & 1 & $3 \%$ & - \\
Journal of Business Venturing lnsights & 1 & $3 \%$ & - \\
Journal of Entrepreneurship Education & 1 & $3 \%$ & 5.647 \\
Journal of Environmental Management & 1 & $3 \%$ & - \\
Journal of International Entrepreneurship & 1 & $3 \%$ & 2.628 \\
Physiology \& Behavior & 1 & $3 \%$ & 4.803 \\
Small Business Economics & 1 & 1 & - \\
Smart and Sustainable Built Environment & 40 & $3 \%$ & - \\
Total & & & \\
\hline
\end{tabular}

\subsection{Definition of the descriptive and analytical categories}

For categorization and analysis of the studies, segmented dimensions were defined according to elements of descriptive nature (type of economy, research method, economic sector of performance) and analytical (opportunity, type of relationship, type of entrepreneur, focus of creation, focus of study). The categories (Table 3) are based on theoretical studies as follows. The defined categories are coded as follows.

\section{Analytical dimensions of the results}

The presentation of the results is segmented according to the different dimensions established in the classification, considering the following ordering: 5.1 Type of Economy, 5.2 Research Method, 5.3 Economic Sector, 5.4 Recognition of Opportunity, 5.5 Type of Relationship, 5.6 Type of Entrepreneur, 5.7 Creation Focus, and 5.8 Study Focus. 
Table 3. Result of analytical categorization.

\begin{tabular}{|c|c|c|c|}
\hline Dimension & Classification & Code & Base \\
\hline \multirow{4}{*}{ Type of economy } & Developed Economy & $1 \mathrm{~A}$ & - \\
\hline & Developing Economy & 1B & - \\
\hline & Comparison between Countries & $1 \mathrm{C}$ & - \\
\hline & Economic Block & $1 \mathrm{D}$ & - \\
\hline \multirow{3}{*}{ Research method } & Single Case Study & $2 \mathrm{~A}$ & - \\
\hline & Multiple Case Study & $2 \mathrm{~B}$ & - \\
\hline & Quantitative Method & $2 \mathrm{C}$ & - \\
\hline \multirow{4}{*}{ Economic sector } & Industry & $3 \mathrm{~A}$ & - \\
\hline & Services & 3B & - \\
\hline & Agriculture & $3 \mathrm{C}$ & - \\
\hline & Does not apply & $3 \mathrm{D}$ & - \\
\hline \multirow{3}{*}{$\begin{array}{l}\text { Recognition of business } \\
\text { opportunities }\end{array}$} & Allocative & $4 \mathrm{~A}$ & \multirow{3}{*}{ Sarasvathy et al. (2003) } \\
\hline & Distributive & $4 \mathrm{~B}$ & \\
\hline & Creative & $4 C$ & \\
\hline \multirow{2}{*}{ Type of relationship } & Causation & $5 \mathrm{~A}$ & \multirow{2}{*}{ Sarasvathy (2001) } \\
\hline & Effectuation & $5 B$ & \\
\hline \multirow{4}{*}{ Type of entrepreneur } & Reproduction & $6 \mathrm{~A}$ & \multirow{4}{*}{ Julien (2010) } \\
\hline & Imitation & $6 \mathrm{~B}$ & \\
\hline & Valuation & $6 C$ & \\
\hline & Adventure & $6 \mathrm{D}$ & \\
\hline \multirow{4}{*}{ Focus of creation } & Enterprise Creation & $7 \mathrm{~A}$ & $\begin{array}{l}\text { Ardichvili et al. (2003); Shane } \\
\text { (2000) }\end{array}$ \\
\hline & Product/Service Creation & $7 \mathrm{~B}$ & $\begin{array}{l}\text { Baron \& Shane (2007); Shane } \\
(2000)\end{array}$ \\
\hline & Networking & $7 \mathrm{C}$ & $\begin{array}{l}\text { Ardichvili et al. (2003); Shane } \\
\text { (2000) }\end{array}$ \\
\hline & Value Creation & 7D & $\begin{array}{l}\text { Ardichvili et al. (2003); Shane } \\
(2000)\end{array}$ \\
\hline \multirow{5}{*}{ Focus of the study } & Product Innovation & $8 \mathrm{~A}$ & Naudé (2011) \\
\hline & Market Failure Exploitation & $8 \mathrm{~B}$ & $\begin{array}{l}\text { Shane \& Venkataraman (2000); } \\
\text { Sarasvathy (2008); Coase (2004) }\end{array}$ \\
\hline & Incubators & $8 \mathrm{C}$ & Morris et al. (2015) \\
\hline & Ecosystem Entrepreneur & $8 \mathrm{D}$ & $\begin{array}{l}\text { Spigel (2017); Malecki (2011); } \\
\text { lsenberg (2010) }\end{array}$ \\
\hline & Regional Development & $8 \mathrm{E}$ & Julien (2010); Schlange (2007) \\
\hline
\end{tabular}

\subsection{Type of economy}

The objective of this category is to map out which contexts studies are produced that contemplate the interface between CE and entrepreneurship. The categories are presented according to Figure 3.

The level of economic development is a determining factor for the type and depth of actions that are taken when analyzing the field of social and environmental concern (Carballo-Penela \& Castromán-Diz, 2015). The type of process, focused on the $\mathrm{CE}$, is related to the maturity of legislation, and above all the propensity of companies and their stakeholders to make commitments to rationalize the use of materials and energy (Randles \& Laasch, 2015). In addition, the existence of subsidies, legal incentives for adhesion to the CE, laws and official resolutions of the country also contribute to the adhesion of organizations to the assumptions of the CE.

\subsection{Method}

In relation to the methods used in the research, it was found that the literature, in its majority, is composed of single or multiple case studies, without much diversity of other forms or modalities of research procedures, as demonstrated in Figure 4. This is understandable, since we are referring to an emerging theme that demands an in-depth understanding in order to make its internalization into organizations possible.

There is, therefore, a research gap regarding the use of different research methods, as well as the use of combinations of methods. The use of little variability of methods, with predominance of case studies, suggests 


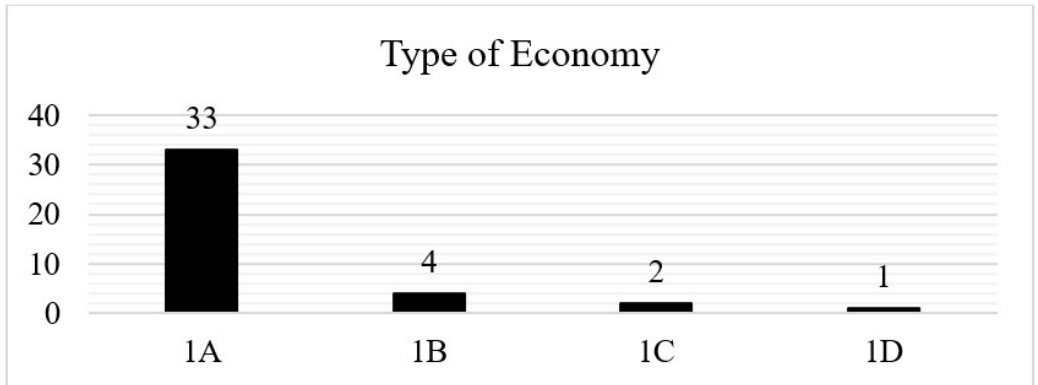

Figure 3. Type of Economy. Code: Developed Economy (1A) - Developing Economy (1B) - Comparison between Countries (1C) Economic Block (1D).

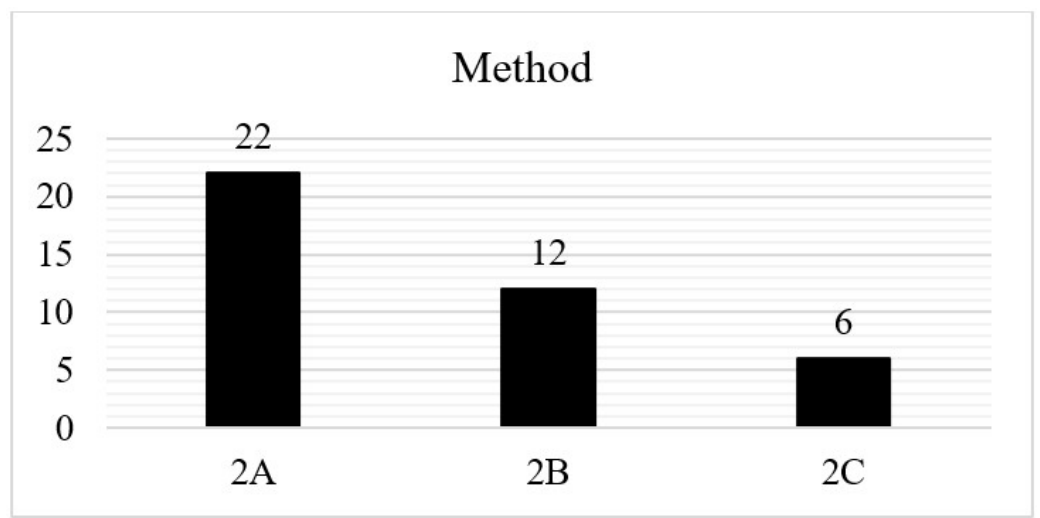

Figure 4. Search Method. Code: Single Case Study (2A) - Multiple Case Study (2B) - Quantitative Method (2C).

that quantitative researches are also employed, according to the possibilities of the research object. Of the studies reviewed, 34 are case studies (single or multiple), and 6 use quantitative method.

\subsection{Economic sector}

The purpose of this category is to identify the sector and branch of activity of the companies focused on systematic review analysis. Figure 5 presents the results.

Of the studies, the concentration occurs in the industrial sector, especially in the energy sector, clean or renewable energy, civil construction, forestry and textiles, totaling 22 cases. From the services sector, 11 studies have been identified, in the area of water and sewage treatment, laundry, sharing platform and health area. Other 2 examples are in the area of conventional or urban agriculture. Finally, 5 studies include diverse sectors.

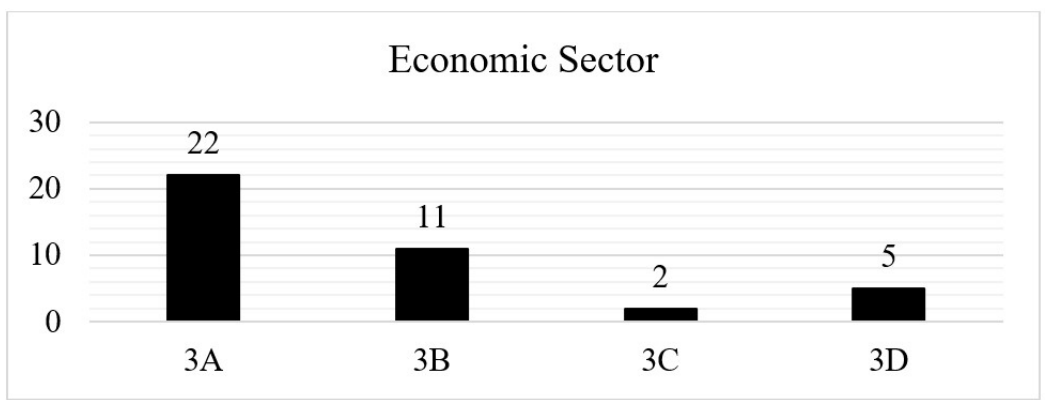

Figure 5. Economic Sector. Code: Industry (3A) - Services (3B) - Agriculture (3C) - Not Applicable (4D). 


\subsection{Recognition of opportunity}

The opportunity recognition dimension is based on the logic proposed in the study by Sarasvathy et al. (2003), which understands that there are three conceptual visions that guide the process of identifying opportunities to undertake. The frequencies are recorded in Figure 6.

The first, allocative view, takes the perception of opportunity as a process of directing potential for the redistribution of resources, from the perspective of supply or demand, so that there is a movement of allocation of existing resources. In this context, six studies were identified. The second, distributive view, is closely related to the discovery process, suggesting that business opportunities arise from asymmetry of information regarding the use of resources, as well as the result of their potential possible combinations. With this profile, there are fifteen studies reviewed. The third, creative view, relates to the creation process, emphasizing the fact that entrepreneurs seek to maximize potentially useful stakeholder functions in order to establish a new market. With this logic, six studies were identified. The three perspectives are mutually exclusive.

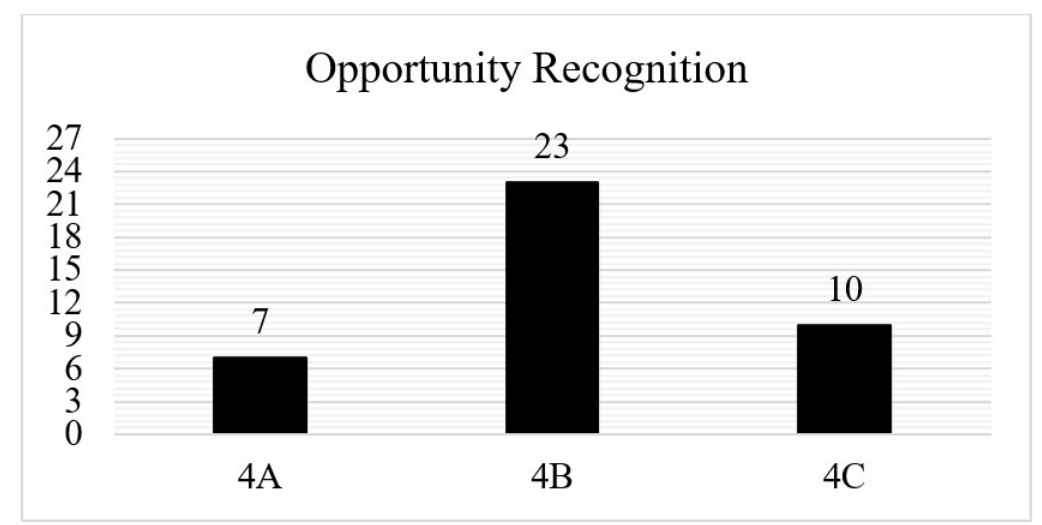

Figure 6. Recognition of Opportunity. Code: Allocative (4A) - Distributive (4B) - Creative (4C).

\subsection{Type of relationship}

This category is related to the variety of the degree of uncertainty of market environments, differentiating itself in causation and effectuation (Sarasvathy, 2001), which can be seen in Figure 7.

The logic of causation is based on the predictability of processes, in which a certain effect or environment is stable, immutable and predictable. With this profile, 29 studies were identified. The logic of the effectuation understands this relationship as a process that begins with a set of means as data and focuses on the selection among the possible effects that can be created, taking the environment as dynamic, with high uncertainty and that demands a high level of creativity. Eleven articles were reviewed with this logic.

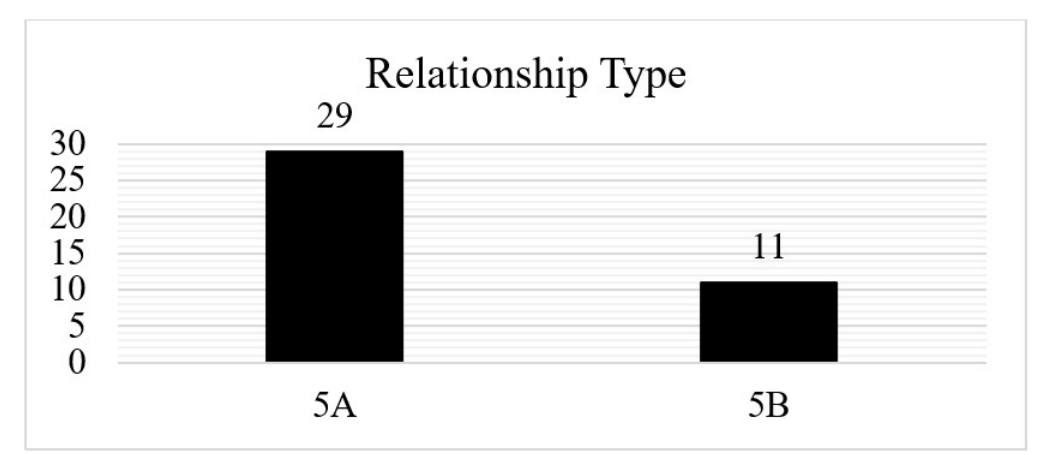

Figure 7. Relationship Type. Code: Causation (5A) - Effectuation (5B). 


\subsection{Type of entrepreneur}

The category of typologies of entrepreneurs, taken from the perspective of Julien (2010), considers innovation as a guiding element and an important feature in value creation. Figure 8 presents the logic of the type of entrepreneur, according to the theoretical contribution.

Considering the argumentation proposed by the author, the reproduction entrepreneur changes little and creates less value. The imitation entrepreneur does not create much new value, but is strongly influenced by this creation. The valorization entrepreneur makes substantial changes and adopts more active strategies. The adventure entrepreneur creates innovative companies and takes considerable risks, and can even form a new economic sector.

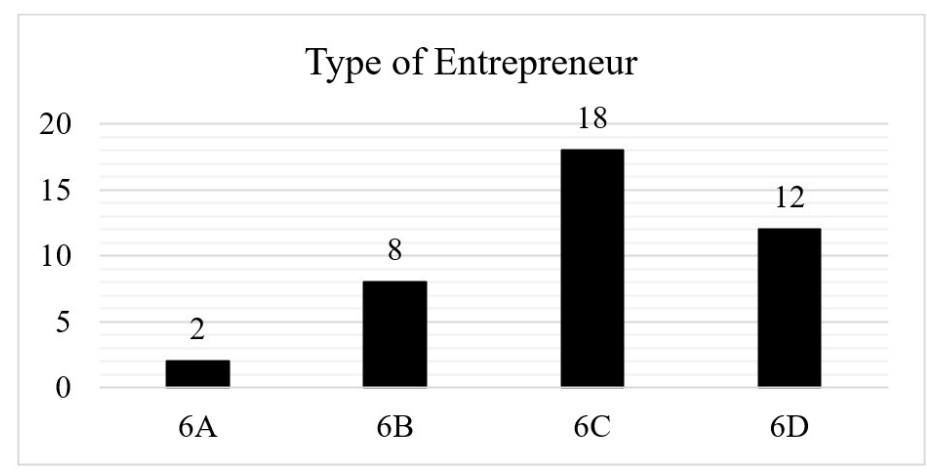

Figure 8. Type of Entrepreneur. Code: Reproduction (6A) - Imitation (6B) - Valuation (6C) - Adventure (6D).

\subsection{Creation focus}

The creation category encompasses different theoretical compositions related to the process of creating the new to what already exists. Figure 9 presents the creation logic.

The generation of the new can occur from the creation of companies (Ardichvili et al., 2003; Shane, 2000), creation of a new product or service (Baron \& Shane, 2007; Shane, 2000), networking (Ardichvili et al., 2003; Shane, 2000) or value creation (Ardichvili et al., 2003; Shane, 2000). Of the studies reviewed, there are multiple possibilities identified for value creation, with greater emphasis on aspects related to value creation (23 cases) and networking (19 cases).

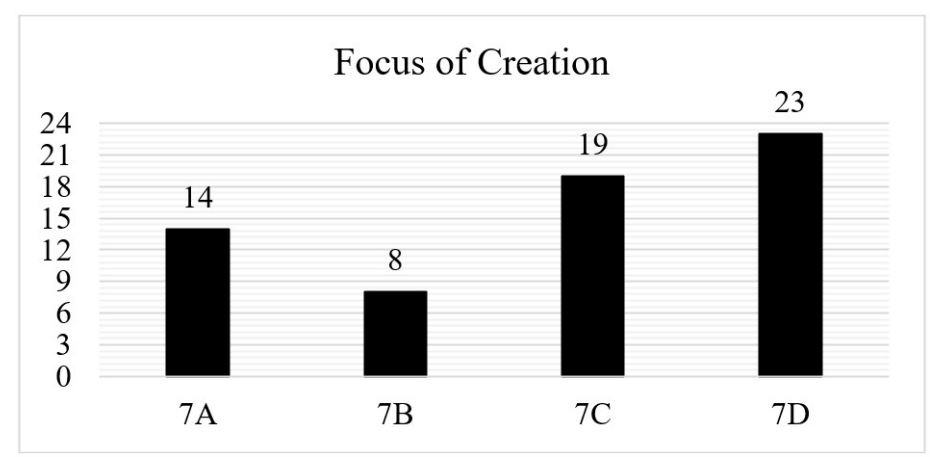

Figure 9. Focus of Creation. Code: Enterprise Creation (7A) - Product/Service Creation (7B) - Network Creation (7C) - Value Creation (7D).

\subsection{Study focus}

The last analytical category comprises the focus taken in conducting studies that relate circular economics and the different perspectives on entrepreneurship. In Figure 10 the studies are arranged according to dimensions. 


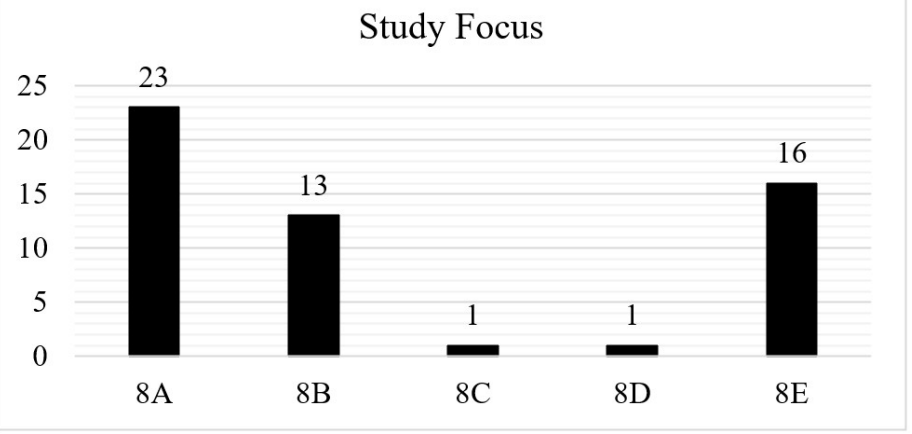

Figure 10. Study Focus. Code: Product Innovation (8A) - Market Failure Exploitation (8B) - Incubators (8C) - Entrepreneurship Ecosystem (8D) - Regional Development (8E).

The process of entrepreneurship encompasses implications for the allocation of scarce resources and for development, going through broad themes of discussion that characterize the direction given to the understanding of entrepreneurship as a phenomenon. The study relates the review of the papers according to the logic of the product innovation criteria (Naudé, 2011), exploration of market failures (Shane \& Venkataraman, 2000; Sarasvathy, 2008; Coase, 2004), entrepreneurship through business incubation (Morris et al., 2015), entrepreneurial ecosystems (Spigel, 2017; Malecki, 2011; lsenberg, 2010) and the perspective of their contributions to regional development (Julien, 2010; Schlange, 2007).

\section{Discussion of results}

The evidence from the study indicates that the interrelationship mapped between the CE and sustainable entrepreneurship constructs presents past studies that were predominantly: elaborated and published by authors located in developed countries, are case or multiple studies, focus on economic sectors industry or services, adopt causation logic, recognize opportunities via distributive models, are fostered by entrepreneurs who imitate others and give emphasis to product innovation. Thus, one can ask what opportunities arise for the advancement of synergy between the concepts of CE and sustainable entrepreneurship, based on this current panorama?

Sustainable entrepreneurship values alternatives that can foster progress towards sustainability and aligned with sustainable development objectives (Nikolaou et al., 2018). And the CE stimulates new, cleaner and more efficient alternatives, capable of transforming waste into inputs for production chains. Alternatives that dematerialize obsolete materials and transform them into useful material for manufacturing new products. It seeks to retain the value of resources in supply chains. Helps to reduce waste and show possibilities to generate disruptive changes in traditional production models.

The guarantee of long-term business sustainability and promotion of the CE as a philosophy that integrates industrial activity with environmental preservation should provide for the decoupling of the increased need for resource consumption from economic growth. It requires a redesign of industrial systems (Razminiene, 2019). To grow without compromising and without stimulating the demand for virgin products, the creation of new business models via the entrepreneurial process is necessary. Entrepreneurs can rely on the assumptions of the CE as an alternative to the linear model of production and consumption to effect the transition to a CE.

The recognition of opportunities to undertake, in this context, is based on a philosophy that stimulates the maximum use of resources already inserted in production processes, the closing of production cycles and the reduction or elimination of production waste generation. New businesses should be oriented to integrate production systems and supply chains in order to accumulate and transfer value along relationship and sharing networks (Canto et al., 2021). Production rejects or waste from a given production process can be re-integrated into another process, which allows the aggregation of value within a chain through transfer. In this case, the waste becomes a resource for production. The value is generated and externalities avoided, since potentially harmful materials to the environment are not removed from production cycles.

Innovation is a necessary condition not only for the transformation of production processes, but above all for changing business models (Lynde, 2020). In the field of management, innovation and change is the alternative to transform companies and adapt them according to the principles of CE or create totally new and free of vices business. But not all companies are prepared or inclined to change their fundamental logic of operation. 
It is in this situational context that market failures arise that can lead to compromised resource availability and business unsustainability. The environmental degradation, generated by linear enterprises, besides being harmful to society and the environment, also does not find a perspective of long-term sustainability. The asymmetry of information and conflict of interests creates market imperfections at the same time as it creates opportunities for those who are already born in line with the CE and sustainability.

Business development via the entrepreneurial process generates the possibility of value creation, networking among suppliers, new products or services, as well as the creation of circular-born companies (Konietzko et al., 2020). The access to information and the formation of a long-term perspective reinforces the notion that entrepreneurs acquire greater projection when connected in networks. As for the aspect of material flows in production processes, the possibility of load transfer between companies qualifies them for the reduction of impacts by disposal. In the macro sense, the formulation of regulations with the definition of goals and responsibilities to different links in the circular transition allows the establishment of guidance on how to proceed to innovate towards the closing of cycles (Singh et al., 2020).

\section{Proposed agenda for future research}

Given the results and discussion developed in the previous sections, this topic presents the possibilities and gaps found, based on the review of articles, in which it is possible to identify the direction that the authors suggest for the development of future studies in the research area. The authors point out, based on the contributions they have made in their reports, clear and precise recommendations for discussions on circular economics and entrepreneurship. The possibilities are shown in Table 4.

Table 4. Indication of Future Research Gaps.

\begin{tabular}{ll}
\hline \multicolumn{1}{c|}{ Author } & \multicolumn{1}{c}{ Research Gap } \\
\hline Bocken et al. (2019) & $\begin{array}{l}\text { Aplication of brainstorming or action-research methods to support the redesign of ecologies of business models more } \\
\text { genvironmental impact. This requires more research on the design and experimentation of sustainable business models, } \\
\text { adopting a system-level perspective. }\end{array}$ \\
Bundgaard et al. (2017) & $\begin{array}{l}\text { Continue to expand work on developing standards that define testing methods and verification procedures on resource } \\
\text { efficiency. }\end{array}$ \\
Neumeyer \& Santos & $\begin{array}{l}\text { Do sustainable entrepreneurial ecosystems share the same components as conventional entrepreneurial ecosystems? } \\
\text { What are the formal and informal rules that define participation in sustainable business ecosystems? How can we define } \\
\text { success in sustainable entrepreneurial ecosystems? }\end{array}$ \\
Hahn et al. (2018). & Study hybrid business models to provide information on the design and management of these organizations.
\end{tabular}

Makropoulos et al.

(2018).

Unay-Gailhard \&

Bojnec (2018).

Criado-Gomis et al.

(2018).

Propose studies for the feasibility of large-scale adoption of sewage mining, presented in the paper in a single case.

D’Amato et al. (2020). Exploring the transition from business models to circular bioeconomy in the context of other industrial bases.

Grinevich et al. (2017)

To investigate the material ecological effects of various sharing models in a holistic way to provide more substance and critical reflections for the green discourse of the shared economy. Additional insights into potential context specificity can be brought by comparative studies of the use of logics in shared economy ventures by entrepreneurial teams in different national, socio-economic and sectoral contexts.

Kinnunen \& Kaksonen Explore the business potential for metal recovery from mining waste, considering the identified barriers that need to be (2019). addressed to accelerate transformation.

Exploring the role of government institutions in the regulation of the model, development and testing of control Lazarevic et al. (2020). policies, through low carbon public procurement criteria and changes in organizational practices of municipalities (reconfiguration between actors and networks).

Veleva \& Bodkin Examining how business model innovations are able to address the rational and irrational motives of consumers and (2018). change their behavior to adopt EC practices (e.g. buy green or remanufactured products, return products for reuse or recycling, rent rather than buy products).

Future studies may consider other different levels of analysis (company level, industry level, country policy level, etc.). In addition, the importance of the demand side as related to market orientation needs more attention in future studies.

Manesh \& Rialp-Criado (2018). Other studies may also address the importance of unexamined environmental factors, such as institutions, energy policy and industry structure, in the entrepreneurial internationalization of new companies competing in this emerging renewable energy industry.

Havierniková \& Kordoš Develop the theme aimed at reducing the threats identified, and subsequently addressing the negative consequences of (2019) these environments. 
Table 4. Continued...

\begin{tabular}{|c|c|}
\hline Author & Research Gap \\
\hline Burzyńska et al. (2018) & $\begin{array}{l}\text { To explore the benefits made possible through assistance, as well as technical and financial support throughout the } \\
\text { process of implementing and monitoring innovations in the textile sector. }\end{array}$ \\
\hline Yoshida et al. (2019) & $\begin{array}{l}\text { Explore possibilities around the financial and strategic management capabilities of farmers, aimed at entrepreneurship or } \\
\text { the maintenance of existing enterprises. }\end{array}$ \\
\hline $\begin{array}{l}\text { Tur-Porcar et al. } \\
\text { (2018). }\end{array}$ & Exploring the ethical components identified in different contexts, seeking to verify differences and similarities. \\
\hline $\begin{array}{l}\text { Davies \& Chambers } \\
\text { (2018). }\end{array}$ & $\begin{array}{l}\text { Explore to what extent a common business model and strategies around governance, marketing, channel and supply } \\
\text { management can ease the tensions associated with multiple ways of capturing value from newly created businesses in } \\
\text { practice. }\end{array}$ \\
\hline $\begin{array}{l}\text { Demirel \& Danisman } \\
\text { (2019) }\end{array}$ & $\begin{array}{l}\text { Analyze the dynamics of the relationship between circular innovation and company performance associated with } \\
\text { business expansion as longitudinal data sets become available. }\end{array}$ \\
\hline Henry et al. (2020). & Define barriers and success factors for the diffusion of business models in the context of the circular economy. \\
\hline Konietzko et al. (2020) & Experimenting with how to compose teams to test business models guided by the circular economy. \\
\hline Lynde (2020). & Evaluate the creation of value for the system by feeding innovations in business models. \\
\hline
\end{tabular}

Predominantly, the studies deal with the theme of CE as a challenge to be addressed, by creating value and networking, expanding successful experiences to other contexts, replicating and exploring market failures as possibilities to create the new, as well as exploring areas that have received little attention so far. The closing of material and energy cycles demands the modification of processes and the institution of less aggressive patterns of production and consumption (Khan et al., 2021). The practical implications, both for organizations and for society, make it possible for researchers to attempt to understand and expand the known area. Based on unexplored gaps, a more assertive path for knowledge production is presented, starting from the points that demand attention.

Based on the triangulation of the gaps pointed out by the authors and on the discussion about the descriptive and analytical categories formulated in the systematic review, the following synthetic scheme is proposed for the development of the research agenda on the subject under analysis, set forth in Table 5 . The scheme points out direct possibilities to be developed for the advancement of the theme, from the theoretical point of view and with managerial implications, with twelve possibilities for future research agenda on the theme.

Table 5. Proposals for Future Research.

\begin{tabular}{|c|c|}
\hline Research Gap & Proposal for Future Research \\
\hline Research locus fragility & Studies of circular economy and entrepreneurship applied to emerging or developing countries. \\
\hline Fragility of the method & Use of qualitative, quantitative or combined research methods. \\
\hline $\begin{array}{l}\text { Concentration of studies in a few branches } \\
\text { of activity }\end{array}$ & $\begin{array}{l}\text { Diversification of economic sectors beyond industries, aiming with more emphasis on services and } \\
\text { biological cycles related to agriculture. Deepening studies on shared economy. }\end{array}$ \\
\hline Business model redesign & $\begin{array}{l}\text { Design and sustainable business models, redesigning the ecology of business models. Expanding } \\
\text { understanding of hybrid business models. }\end{array}$ \\
\hline Verification of effective resource efficiency & Expanding the development of testing and verification methods for resource efficiency. \\
\hline Gains in scale & Seek elements to enable the adoption of circular economy gains from scale. \\
\hline Performance & Explore sustainable entrepreneurial strategic orientation and its effects on performance. \\
\hline Extrapolation of results & $\begin{array}{l}\text { Extrapolate circular business models to contexts beyond the context to which it was designed, when } \\
\text { possible and feasible. }\end{array}$ \\
\hline Sustainable consumption & $\begin{array}{l}\text { Approach the rational and irrational motives of consumers in changing their consumption behavior } \\
\text { with a focus on products based on circular economy. }\end{array}$ \\
\hline Sustainable Entrepreneurship Ecosystems & $\begin{array}{l}\text { To explore the role of institutional environments destined to create businesses aligned to the } \\
\text { principles of circular economy, since its genesis. }\end{array}$ \\
\hline Role of Institutions & $\begin{array}{l}\text { Exploration of the role of government agents and regulatory agencies in promoting the creation of } \\
\text { enterprises with circular characteristics. }\end{array}$ \\
\hline $\begin{array}{l}\text { Consideration of unstudied environmental } \\
\text { factors }\end{array}$ & $\begin{array}{l}\text { Addressing the importance of unexamined environmental factors, such as institutions, energy policy } \\
\text { and industry structure, in entrepreneurial internationalization. }\end{array}$ \\
\hline
\end{tabular}

The various opportunities for creating circular value are alternatives that can be explored to strengthen and generate new business models (Lynde, 2020). Entrepreneurs who take advantage of the opportunities generated by the policies and regulations that guide the CE can generate ways to reduce their expenses and improve 
company performance (Tura et al., 2019). Government incentives for circular transition and principled business creation have full potential for increased employment opportunities, so-called green work, improved policies to support the environmental aspect, less waste disposal and higher level of reuse, lower demand for virgin raw materials (Konietzko et al., 2020).

The new business models proposed by the circular logic aim at innovation, advancement and systemic incorporation of environmental value (Lynde, 2020). The CE is a path to achieving sustainable development, reducing externalities in the environment and reducing exploitation of natural resources and environmental change (Völker et al., 2020). The premise of closing production cycles, with reduction or elimination of resource outflow and waste generation promotes business activity aligned with sustainability (Henry et al., 2020). Closing cycles implies providing resource efficiency and optimization, resilience, resource-oriented flow generation, innovative products and services, while at the same time enhancing the utility and use of resources (Millette et al., 2020).

\section{Final remarks, contributions and limitations of the research}

The creation of new business models guided by the principles of CE has evolved substantially towards obtaining the closure of production cycles, reducing emissions and optimizing the utility of resources. Regulations at the government level to foster initiatives and progress in the field demand implementation at the level of companies and products. The proposition of innovative businesses flows with the effort to advance the CE and innovation in the way companies are transformed by the circular transition. This review, developed with the objective of exploring the relationship between the CE and entrepreneurship, proposing an agenda for future research to advance in the field and generate managerial implications on the subject, contributes to the understanding of the logic that governs this dynamic.

The creation of new businesses or the modification of existing ones is an alternative to propose business models aligned with the principles of the circular economy. In this sense, the exploration of the characteristics of previous studies provides knowledge about the advances already undertaken in this specific field. Knowing the interactions between both areas allows the extrapolation of theoretical and managerial implications to propose paths for future advancement. In practical terms, Accenture points out that the transition to the circular economy can contribute with up to $45 \%$ reduction in the emission of greenhouse gases and bring financial gains in the order of 4.5 trillion dollars by 2030 in waste reductions, efficiency and creating new jobs globally (Accenture Strategy, 2015). Therefore, it is important to know the progress already made and to look for new ways to build knowledge in the field and advance practices.

The articles were categorized in 8 dimensions that group the context and the orientation that the articles assume. The axes of analysis are segmented and summarized as to aspects associated with the objectives, main findings and results of research, theoretical and practical contributions to the field. The central themes in the studies about CE and entrepreneurship are associated to the following topics: i) type of economy, which refers to the development context of the study, ii) research method, iii) exploited economic sector, iv) recognition of business opportunity, directly associated to the opportunity to undertake, v) type of relationship, in which the logic of how to undertake is extracted, vi) type of entrepreneurship, vii) creation focus, referring to the creation process inherent to the action to undertake, viii) study focus, which analyzes the predominant area of the study. The different studies and categories synthesize the initiatives and areas in which the possibilities of circular business creation, conditioned by the action to undertake, are under development and contribute to the circularity, aggregation of value and extension of the utility and use of resources.

This research contributes by mapping and organizing the thematic axes and areas of interest explored by studies focusing on CE and entrepreneurship. Categories associated with the creation of businesses in the circular context are described and analyzed with respect to theoretical elements specific to the field. The organization of the review systematizes an area that is still little explored, which reveals interesting opportunities for advancement, especially with regard to practice. To the scholars of entrepreneurship and CE, it is important to define paths and assertive ways for knowledge production and development acceleration from research insights. Given the high dynamism and evolution of the themes, a review to consolidate the theoretical and practical advances is relevant, especially to give foundation to future studies that explore the theme.

In the practical aspect, the research signals to decision makers and policy makers possibilities for the CE to advance from the creation of new businesses totally guided by circular principles. In the management area, the main increments towards the CE occur by the proposition of conscious business models and guided by obtaining sustainable value and optimizing the utility of resources. Both themes have an intrinsic relationship, since it is possible to confer mutual advances by their complement. 
The article is limited in the number of articles analyzed. Although the search for research has been extensive, operated in 10 different databases, the final return of articles suitable and aligned to the scope studied has been reduced. This limits the scope and generalization of the results obtained. The option to select only peerreviewed articles was made in order to increase the quality of the results. However, it is possible that other relevant documents, from grey literature for example, have not been appreciated. Finally, the codification adopted by the authors is limited to the possibility of interpretation, which may limit or create bias in the analysis. It is recommended that in future researches categories be proposed in addition to those already adopted, as well as extending the review to verify the effects of the relationship between CE and entrepreneurship with interface to the achievement of sustainable development objectives.

\section{References}

Accenture Strategy. (2015). SMARTer2030: ICT solutions for 21st century challenges (Tech. Rep.). Brussels: The Global eSustainability Initiative (GeSI).

Alonso-Almeida, M. M., Rodriguez-Anton, J. M., Bagur-Femenías, L., \& Perramon, J. (2021). Institutional Entrepreneurship enablers to promote circular economy in the European Union: Impacts on transition towards a more circular economy. Journal ofCleaner Production, 281, 124841. http://dx.doi.org/10.1016/j.jclepro.2020.124841.

Amoako, G. K., Bonsu, G. A., Caesar, L. D., \& Osei-Tete, F. (2021). Finding the nexus between green supply chain practices and sustainable business advantage: an emerging market perspective. Management of Environmental Quality, 32(6), 1133-1149. http:// dx.doi.org/10.1108/MEQ-12-2019-0287.

Antikainen, M., \& Valkokari, K. (2016). A framework for sustainable circular business model innovation. Technology Innovation Management Review, 6(7), 1-12.

Ardichvili, A., Cardozo, R., \& Ray, S. (2003). Theory of Entrepreneurial opportunitty, identification and development. Journal of Business Venturing, 18(1), 105-123. http://dx.doi.org/10.1016/S0883-9026(01)00068-4.

Bansal, A. K., Das, G., Pandey, S., Ghosh, A., Kapoor, S., Qadeer, M. S., Singh, I. V., \& Gani, K. M. (2020). Implementation of Sustainable Green Technologies in Waste Management. Journal of Public Affairs, e2319.

Baron, R., \& Shane, S. (2007). Entrepreneurship: a process perspective. Toronto: Nelson Education.

Bocken, N., Boons, F., \& Baldassarre, B. (2019). Sustainable business model experimentation by understanding ecologies of business models. Journal of Cleaner Production, 208, 1498-1512. http://dx.doi.org/10.1016/j.jclepro.2018.10.159.

Brendzel-Skowera, K. (2019). Circular economy in the development of sustainable entrepreneurship. In Proceedings of the 33rd International Business Information Management Association Conference, IBIMA 2019: Education Excellence and Innovation Management through Vision (pp. 8390-8399). King of Prussia, PA: International Business Information Management Association.

Bressanelli, G., Saccani, N., Pigosso, D. C., \& Perona, M. (2020). Circular economy in the WEEE industry: a systematic literature review and a research agenda. Sustainable Production and Consumption, 23, 174-188. http://dx.doi.org/10.1016/j.spc.2020.05.007.

Bundgaard, A. M., Mosgaard, M. A., \& Remmen, A. (2017). From energy efficiency towards resource efficiency within the Ecodesign Directive. Journal of Cleaner Production, 144, 358-374. http://dx.doi.org/10.1016/j.jclepro.2016.12.144.

Burzyńska, D., Jabłońska, M., \& Dziuba, R. (2018). Opportunities and conditions for the development of green entrepreneurship in the polish textile sector. Fibres \& Textiles in Eastern Europe, 26(2), 13-19. http://dx.doi.org/10.5604/01.3001.0011.5733.

Canto, N. R., Bossle, M. B., Marques, L., \& Dutra, M. (2021). Supply chain collaboration for sustainability: a qualitative investigation of food supply chains in Brazil. Management of Environmental Quality, 32(6), 1210-1232. http://dx.doi.org/10.1108/MEQ-12-2019-0275.

Carballo-Penela, A., \& Castromán-Diz, J. L. (2015). Environmental policies for sustainable development: an analysis of the drivers of proactive environmental strategies in the service sector. Business Strategy and the Environment, 24(8), 802-818. http://dx.doi. org/10.1002/bse. 1847 .

Chiappetta Jabbour, C. J., Sarkis, J., Lopes de Sousa Jabbour, A. B., Scott Renwick, D. W., Singh, S. K., Grebinevych, O., Kruglianskas, 1., \& Filho, M. G. (2019). Who is in charge? A review and a research agenda on the 'human side' of the circular economy. Journal of Cleaner Production, 222, 793-801. http://dx.doi.org/10.1016/j.jclepro.2019.03.038.

Coase, D. (2004). The institutional structure of production. In C. Ménard \& M. Shirley (Eds.), Handbook of new institutional economics. The Netherlands: Kluwer Academic Press.

Criado-Gomis, A., Iniesta-Bonillo, M. Á., \& Cervera-Taulet, A. (2018). Sustainable entrepreneurial orientation within an intrapreneurial context: effects on business performance. The International Entrepreneurship and Management Journal, 14(2), 295-308. http:// dx.doi.org/10.1007/s11365-018-0503-x.

Criado-Gomis, A., Iniesta-Bonillo, M. Á., \& Cervera-Taulet, A. (2018). Sustainable entrepreneurial orientation within an intrapreneuria context: effects on business performance. The International Entrepreneurship and Management Journal, 14(2), 295-308. http:// dx.doi.org/10.1007/s11365-018-0503-x.

Cullen, U. A., \& De Angelis, R. (2021). Circular entrepreneurship: A business model perspective. Resources, Conservation and Recycling, 168, 105300. http://dx.doi.org/10.1016/j.resconrec.2020.105300.

D’Amato, D., Veijonaho, S., \& Toppinen, A. (2020). Towards sustainability? Forest-based circular bioeconomy business models in Finnish SMEs. Forest policy and economics, 170, 101848. https://doi.org/10.1016/j.forpol.2018.12.004.

Davies, l. A., \& Chambers, L. (2018). Integrating hybridity and business model theory in sustainable entrepreneurship. Journal of Cleaner Production, 177, 378-386. http://dx.doi.org/10.1016/j.jclepro.2017.12.196.

Defourny, J., \& Nyssens, M. (2012). Conceptions of social enterprise in Europe: a comparative perspective with the United States. In B. Gidron \& Y. Hasenfeld (Eds.), Social enterprises (pp. 71-90). London: Palgrave Macmillan. http://dx.doi.org/10.1057/9781137035301_4. 
Demirel, P., \& Danisman, G. O. (2019). Eco-innovation and firm growth in the circular economy: Evidence from European small- and medium-sized enterprises. Business Strategy and the Environment, 28(8), 1608-1618. http://dx.doi.org/10.1002/bse.2336.

Fernandes, S. C., Pigosso, D. C., McAloone, T. C., \& Rozenfeld, H. (2020). Towards product-service system oriented to circular economy: A systematic review of value proposition design approaches. Journal of Cleaner Production, 257, 120507. http://dx.doi.org/10.1016/j. jclepro.2020.120507.

Flygansvær, B., Dahlstrom, R., \& Nygaard, A. (2019). Green innovation in recycling: a preliminary analysis of reversed logistics in Norway. World Review of Entrepreneurship, Management and Sustainable Development, 15(6), 719-733. http://dx.doi.org/10.1504/ WREMSD.2019.104860.

Frishammar, J., \& Parida, V. (2019). Circular business model transformation: A roadmap for incumbent firms. California Management Review, 61(2), 5-29. https://doi.org/10.1177/0008125618811926.

Grinevich, V., Huber, F., Karata $\square$-Özkan, M., \& Yavuz, Ç. (2017). Green entrepreneurship in the sharing economy: utilising multiplicity of institutional logics. Small Business Economics, 52(4), 859-876. http://dx.doi.org/10.1007/s11187-017-9935-x.

Hahn, R., Spieth, P., \& Ince, 1. (2018). Business model design in sustainable entrepreneurship: llluminating the commercial logic of hybrid businesses. Journal of Cleaner Production, 176, 439-451. http://dx.doi.org/10.1016/j.jclepro.2017.12.167.

Havierniková, K., \& Kordoš, M. (2019). Selected risks perceived by SMEs related to sustainable entrepreneurship in case of engagement into cluster cooperation. Entrepreneurship and Sustainability lssues, 64), 1680-1693. http://dx.doi.org/10.9770/jesi.2019.6.4(9).

Henry, M., Bauwens, T., Hekkert, M., \& Kirchherr, J. (2020). A typology of circular start-ups: An Analysis of 128 circular business models. Journal of Cleaner Production, 245, 118528. http://dx.doi.org/10.1016/j.jclepro.2019.118528.

Heshmati, A. (2017). A Review of the Circular Economy and its Implementation. International Journal of Green Economics, 11(3-4), 251-288. http://dx.doi.org/10.1504/1JGE.2017.089856.

lsenberg, D. J. (2010). How to start an entrepreneurial revolution. Harvard Business Review, 88(6), 40-50.

Julianelli, V., Caiado, R. G. G., Scavarda, L. F., \& Cruz, S. P. D. M. F. (2020). Interplay between reverse logistics and circular economy: critical success factors-based taxonomy and framework. Resources, Conservation and Recycling, 158, 104784. http://dx.doi. org/10.1016/j.resconrec.2020.104784.

Julien, P. A. (2010). Empreendedorismo regional e economia do conhecimento. São Paulo: Saraiva.

Khan, R., Awan, T. M., Fatima, T., \& Javed, M. (2021). Driving forces of green consumption in sharing economy. Management of Environmental Quality, 32(1), 41-63. http://dx.doi.org/10.1108/MEQ-03-2020-0052.

Kinnunen, P. H.-M., \& Kaksonen, A. H. (2019). Towards circular economy in mining: Opportunities and bottlenecks for tailings valorization. Journal of Cleaner Production, 228, 153-160. http://dx.doi.org/10.1016/j.jclepro.2019.04.171.

Konietzko, J., Baldassarre, B., Brown, P., Bocken, N., \& Hultink, E. J. (2020). Circular business model experimentation: Demystifying assumptions. Journal of Cleaner Production, 277, 122596. http://dx.doi.org/10.1016/j.jclepro.2020.122596.

Kravchenko, M., Pigosso, D. C., \& McAloone, T. C. (2020). A procedure to support systematic selection of leading indicators for sustainability performance measurement of circular economy initiatives. Sustainability, 12(3), 951. http://dx.doi.org/10.3390/su12030951.

Kristensen, H. S., \& Mosgaard, M. A. (2020). A review of micro level indicators for a circular economy-moving away from the three dimensions of sustainability? Journal of Cleaner Production, 243, 118531. http://dx.doi.org/10.1016/j.jclepro.2019.118531.

Lazarevic, D., Kautto, P., \& Antikainen, R. (2020). Finland's wood-frame multi-storey construction innovation system: analysing motors of creative destruction. Forest Policy and Economics, 110, 101861. http://dx.doi.org/10.1016/j.forpol.2019.01.006.

Lynde, R. (2020). Innovation \& entrepreneurship driving food system transformation. Physiology \& Behavior, 220, 112866. http:// dx.doi.org/10.1016/j.physbeh.2020.112866. PMid:32156557.

Makropoulos, C., Rozos, E., Tsoukalas, I., Plevri, A., Karakatsanis, G., Karagiannidis, L., Makri, E., Lioumis, C., Noutsopoulos, C., Mamais, D., Rippis, C., \& Lytras, E. (2018). Sewer-mining: a water reuse option supporting circular economy, public service provision and entrepreneurship. Journal of Environmental Management, 216, 285-298. http://dx.doi.org/10.1016/j.jenvman.2017.07.026. PMid:28728973.

Malecki, E. J. (2011). Connecting local entrepreneurial ecosystems to global innovation networks: open innovation, double networks and knowledge integration. International Journal of Entrepreneurship and Innovation Management, 14(1), 36-59. http://dx.doi. $\operatorname{org} / 10.1504 / 1 J E I M .2011 .040821$.

Manesh, S. M., \& Rialp-Criado, A. (2018). International ecopreneurs: The case of eco-entrepreneurial new ventures in the renewable energy industry. Journal of International Entrepreneurship, 17(1), 103-126. http://dx.doi.org/10.1007/s10843-017-0222-3.

Millette, S., Eiríkur Hull, C., \& Williams, E. (2020). Business incubators as effective tools for driving circular economy. Journal of Cleaner Production, 266, 121999. http://dx.doi.org/10.1016/j.jclepro.2020.121999.

Morris, M. H., Neumeyer, X., \& Kuratko, D. (2015). A portfolio perspective on entrepreneurship and economic development. Small Business Economics, 45(4), 713-728. http://dx.doi.org/10.1007/s11187-015-9678-5.

Naudé, W. (2011). Entrepreneurship is not a binding constraint on growth and development in the poorest countries. World Development, 39(1), 33-44. http://dx.doi.org/10.1016/j.worlddev.2010.05.005.

Neumeyer, X., \& Santos, S. C. (2018). Sustainable business models, venture typologies, and entrepreneurial ecosystems: a social network perspective. Journal of Cleaner Production, 172, 4565-4579. http://dx.doi.org/10.1016/j.jclepro.2017.08.216.

Nikolaou, 1. E., Tsagarakis, K. P., \& Tasopoulou, K. (2018). An examination of ecopreneurs' incentives through a combination between institutional and resource-based approach. Management of Environmental Quality, 29(2), 195-215. http://dx.doi.org/10.1108/ MEQ-01-2017-0004.

Peiró, L. T., Polverini, D., Ardente, F., \& Mathieux, F. (2020). Advances towards circular economy policies in the EU: the new Ecodesign regulation of enterprise servers. Resources, Conservation and Recycling, 154, 104426. http://dx.doi.org/10.1016/j.resconrec.2019.104426.

Pizzi, S., Leopizzi, R., \& Caputo, A. (2021). The enablers in the relationship between entrepreneurial ecosystems and the circular economy: the case of circularity. com. Management of Environmental Quality. In press. http://dx.doi.org/10.1108/MEQ-01-2021-0011. 
Randles, S., \& Laasch, O. (2015). Theorising the Normative Business Model. Organization \& Environment, 29(1), 53-73. http://dx.doi. org/10.1177/1086026615592934.

Razminiene, K. (2019). Circular economy in clusters' performance evaluation. Equilibrium. Quarterly Journal of Economics and Economic Policy, 14(3), 537-559. http://dx.doi.org/10.24136/eq.2019.026.

Rey-Martí, A., Díaz-Foncea, M., \& Alguacil-Marí, P. (2021). The determinants of social sustainability in work integration social enterprises: the effect of entrepreneurship. Economic Research-Ekonomska Istraživanja, 34(1), 929-947. http://dx.doi.org/10.108 0/1331677X.2020.1805348.

Sarasvathy, S. D. (2001). Causation and Effectuation: Towards a theoretical shift from economic inevitability to entrepreneurial contingency. Academy of Management Review, 26(2), 243-288. http://dx.doi.org/10.2307/259121.

Sarasvathy, S. D. (2008). Effectuantion: elements of entrepreneurship expertise. Northampton: Edward Elgar Publishing. http://dx.doi. org/10.4337/9781848440197.

Sarasvathy, S. D., Dew, N., Velamuri, R., \& Venkataraman, S. (2003). Three views of entrepreneurial opportunity. In Z. J. Acs \& D. B. Audretsch (Eds.), Handbook of entrepreneurship research: an interdisciplinary survey and introduction (pp. 141-160). Boston: Kluwer.

Schaltegger, S. (2002). A framework for ecopreneurship. Greener Management International, 2002(38), 45-58. http://dx.doi.org/10.9774/ GLEAF.3062.2002.su.00006.

Schaltegger, S., Lüdeke-Freund, F., \& Hansen, E. G. (2016). Business models for sustainability: a co-evolutionary analysis of sustainable entrepreneurship, innovation, and transformation. Organization \& Environment, 29(3), 264-289. http://dx.doi. org/10.1177/1086026616633272.

Schlange, L. E. (2007). Stakeholder perception in sustainable entrepreneurship: the role of managerial and organizational cognition. In First World Symposium on Sustainable Entrepreneurship as part of the Corporate Responsibility Research Conference (pp. 15-17). Leeds: University of leeds.

Shane, S. (2000). Prior knowledge and the discovery of entrepreneurial opportunities. Organization Science, 11(4), 448-469. http:// dx.doi.org/10.1287/orsc.11.4.448.14602.

Shane, S., \& Venkataraman, S. (2000). The promise of entrepreneurship as a field of research. Academy of Management Review, 25(1), 217-226. http://dx.doi.org/10.5465/amr.2000.2791611.

Singh, A., Gurtu, A., \& Singh, R. K. (2020). Selection of sustainable transport system: a case study. Management of Environmental Quality, 32(1), 100-113. http://dx.doi.org/10.1108/MEQ-03-2020-0059.

Singh, S. K., \& Singh, A. P. (2019). Interplay of organizational justice, psychological empowerment, organizational citizenship behavior, and job satisfaction in the context of circular economy. Management Decision, 57(4), 937-952. http://dx.doi.org/10.1108/MD-092018-0966.

Spigel, B. (2017). The relational organization of entrepreneurial ecosystems. entrepreneurship. Theory into Practice, 41(1), 49-72. http:// dx.doi.org/10.1111/etap.12167.

Tranfield, D., Denyer, D., \& Smart, P. (2003). Towards a methodology for developing evidence-informed management knowledge by means of systematic review. British Journal of Management, 14(3), 207-222. http://dx.doi.org/10.1111/1467-8551.00375.

Tura, N., Hanski, J., Ahola, T., Ståhle, M., Piiparinen, S., \& Valkokari, P. (2019). Unlocking circular business: a framework of barriers and drivers. Journal of Cleaner Production, 212, 90-98. http://dx.doi.org/10.1016/j.jclepro.2018.11.202.

Tur-Porcar, A., Roig-Tierno, N., \& Llorca Mestre, A. (2018). Factors affecting entrepreneurship and business sustainability. Sustainability, 10(2), 452. http://dx.doi.org/10.3390/su10020452.

Unay-Gailhard, İ., \& Bojnec, ک̌. (2018). The impact of green economy measures on rural employment: green jobs in farms. Journal of Cleaner Production. http://dx.doi.org/10.1016/j.jclepro.2018.10.160.

Veleva, V., \& Bodkin, G. (2018). Corporate-entrepreneur collaborations to advance a circular economy. Journal of Cleaner Production, 188, 20-37. http://dx.doi.org/10.1016/j.jclepro.2018.03.196.

Völker, T., Kovacic, Z., \& Strand, R. (2020). Indicator development as a site of collective imagination? The case of European Commission policies on the circular economy. Culture and Organization, 26(2), 1-18. http://dx.doi.org/10.1080/14759551.2019.1699092.

Yoshida, S., Yagi, H., Kiminami, A., \& Garrod, G. (2019). Farm diversification and sustainability of multifunctional peri-urban agriculture: entrepreneurial attributes of advanced diversification in Japan. Sustainability, 11(10), 2887. http://dx.doi.org/10.3390/su11102887. 